\title{
Sobre la Teoría y la Práctica
}

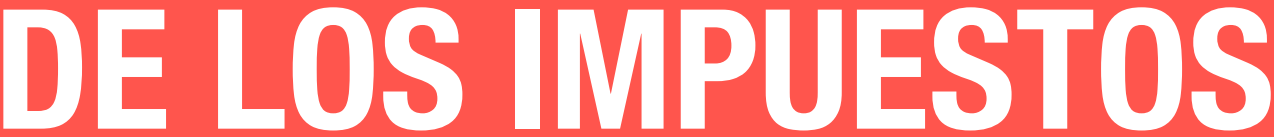

\section{Luego de recién asumido el nuevo Gobierno del Presidente Piñera, ya se plantean algunos cambios a la estructura tributaria que no deberian ser indiferentes para los chilenos.}

Rafael Romero Meza ,DBA en Finanzas, Boston University, Estados Unidos. Académico FEN UAH

I hablar de impuestos es un tema complejo. ¿A quién le gusta pagar impuestos? Independientemente de nuestras preferencias particulares, lo cierto es que los impuestos forman parte de las sociedades modernas. Los estados tienen compromisos de provisión de ciertos bienes o servicios sociales como salud, educación y defensa, los que requieren ser financiados.

Dada esta realidad, se espera que los impuestos logren como objetivo primario alcanzar una cierta recaudación y que esta sea al menor costo social $^{1}$ posible. Adicionalmente, se le atribuye a impuestos y su contraparte subsidios la posibilidad de corregir ciertas situaciones en que el equilibrio de mercado, sin intervención, no lograría una asignación óptima, o un balance políticamente deseable.

El propósito de este artículo es revisar algunos elementos de la teoría económica sobre los impuestos óptimos a las transacciones y luego concluir sobre aspectos prácticos de una eventual alza de impuesto, teniendo en mente el objetivo recaudatorio y los costos sociales asociados a ellos.

En Chile uno de los principales mecanismos de recaudación del Estado son los impuestos y existen tres grandes grupos, los denominados Directos (Renta), Indirectos (Transacciones como el IVA) y Otros (al Patrimonio).

A continuación revisaremos las lecciones de la teoría económica para ayudar a definir algunas reglas que contribuyan a definir un impuesto a las transacciones, como es el IVA, óptimo. Para esto revisaremos la incidencia de un impuesto o sobre quién recae finalmente el impuesto y de qué variables depende.

\section{INCIDENCIA DE UN IMPUESTO}

\section{A LASTRANSACCIONES}

Cuando un bien es gravado con un impuesto, este posee dos precios (uno con impuesto y otro sin impuesto), los compradores solo ven el precio con impuesto (ya que este es lo que ellos pagan por el bien). Lo anterior conlleva a situaciones de desequilibrio las cuales detallamos a continuación gráficamente.

En la siguiente gráfica, el punto $A$, ilustra un equilibrio de mercado sin impuestos. Si el gobierno aplica un impuesto a la venta (o quizás eleva el actual) de $\$$ T por unidad o $\$ 5$, lo cual elevará el precio a $\$ 10$. Por otra parte, la oferta $(\mathrm{S})$ se desplaza a $\mathrm{S}+\mathrm{T}$ generando un nuevo equilibrio momentáneo en B. El impuesto a la venta resulta similar a un aumento de costos, y al aumentar el precio la cantidad demandada se reduce hasta el

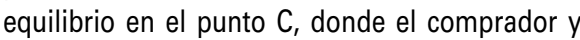
el vendedor absorben en parte el alza del bien, debido a los impuestos. La división del impuesto entre el comprador y vendedor dependerán de las elasticidades de la demanda y de la oferta.

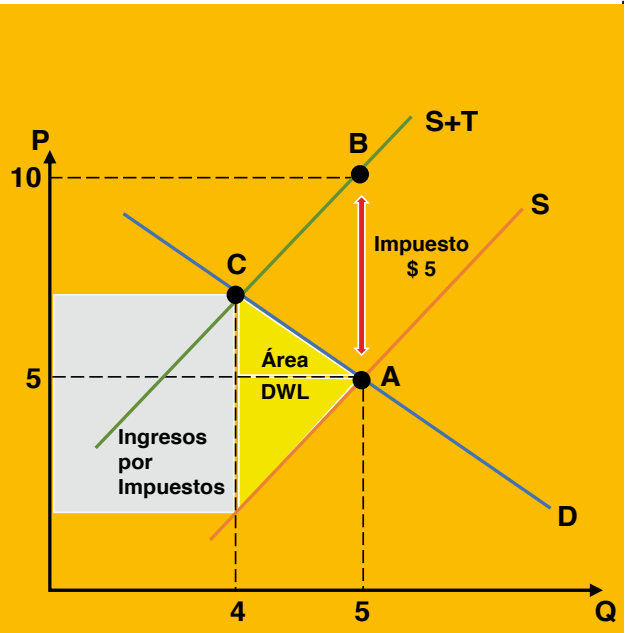

Del gráfico anterior, se puede concluir que el tamaño de la pérdida social o DWL (deadweight loss) definida como la reducción del bienestar en exceso de la recaudación tributaria, que en el gráfico se representa por el área del triángulo, está dado por:

$$
\text { Pérdida Social }=\frac{1}{2} \varepsilon \frac{x^{0}}{p} T^{2}
$$

Donde, $p=5$ es la elasticidad de demanda, medida en valor absoluto. $x^{0}=5$ es la cantidad demandada antes de impuesto, $\varepsilon^{d}$ es el nivel de precio inicial y es el monto del impuesto por unidad.

De la fórmula anterior, se puede concluir que la Pérdida Social es proporcional al monto del impuesto. Por lo que la ella crecerá rápidamente con el incremento del impuesto. Además, la Pérdida Social es proporcional a la elasticidad de la demanda. Para un cierto cambio de impuesto, la Pérdida Social será mayor mientras más elástica es la demanda por el bien o servicio.

Acabamos de revisar de qué depende el tamaño de la Pérdida Social considerando un solo bien. Un resultado más general que está sujeto a ciertos supuestos, establece lo que es conocido como la Regla de la Elasticidad Inversa.

\section{LA REGLA DE LA ELASTICIDAD INVERSAY}

ASPECTOS DE EQUIDAD EN LATASA DE IMPUESTO

Un supuesto simplificador es que los bienes son independientes en demanda, tal que no hay efectos cruzados de precios entre los bienes. Se busca una asignación óptima, tomando en consideración el monto requerido de recaudación por impuesto y de ella se quiere inferir las tasas de impuesto consistentes con esa solución.

La Regla de la Elasticidad Inversa establece que la tasa proporcional de impuesto sobre un bien debería ser inversamente relacionado a su elasticidad precio de demanda. Esto significa que en términos de Pérdida Social, se imponga una tasa 


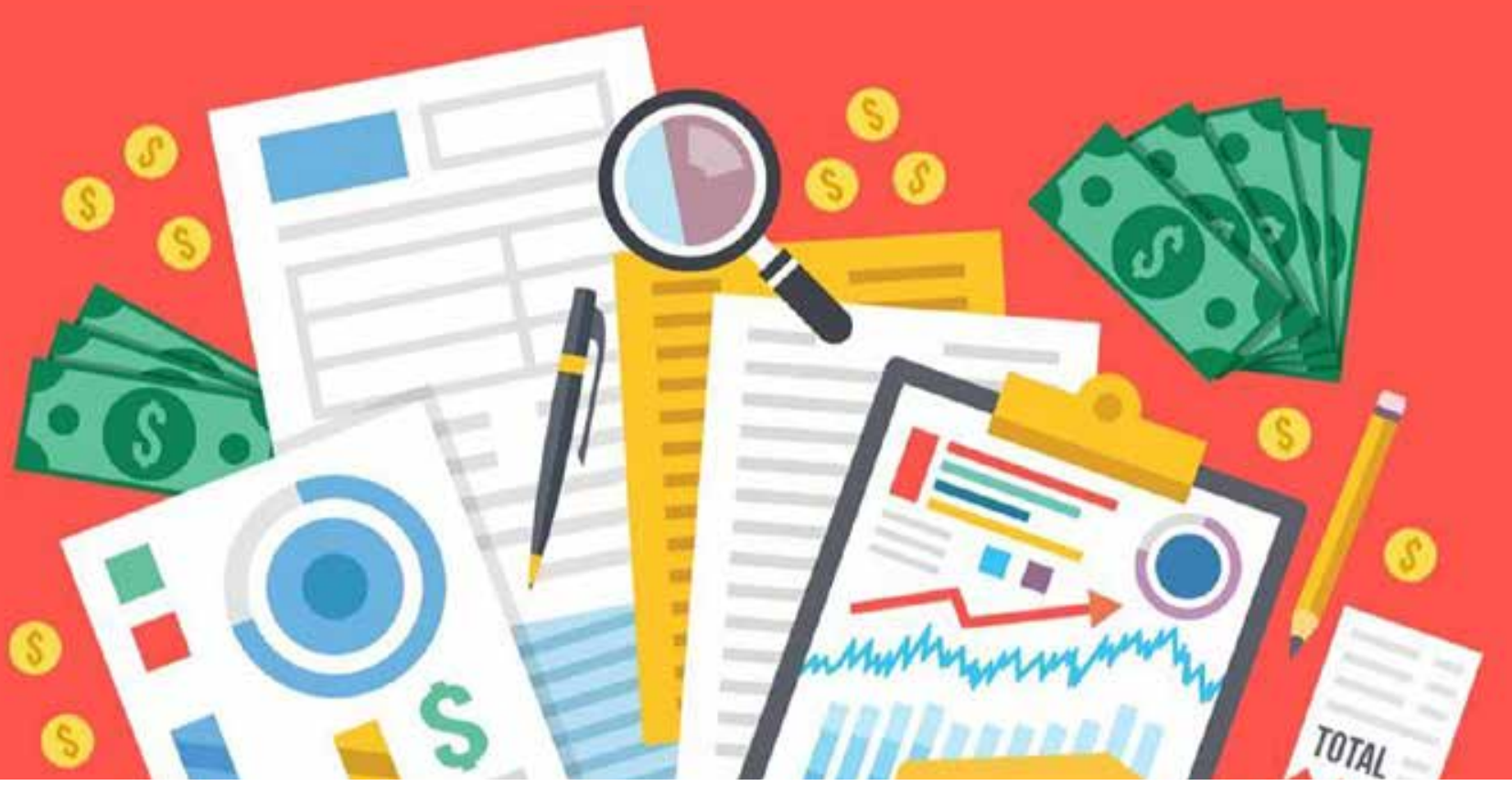

de impuesto mayor sobre bienes cuya demanda es más inelástica.

Este análisis no considera aspectos de equidad en la tasa de impuesto. Al introducir equidad, es decir considerando consumidores de bajos ingresos y de altos ingresos, el resultado es un sistema de impuestos diferenciados, que dependen de variables adicionales a la elasticidad de demanda. Así el resultado se puede establecer como que aquellos bienes que son consumidos principalmente por los pobres deberían tener menos impuesto.

El problema práctico para la implementación de un sistema tributario diferenciado es conocer las funciones de bienestar de muchos individuos, lo cual es un problema no resuelto en economía. Dado lo anterior, la solución que han adoptado la mayoría de los estados es establecer un impuesto con una misma tasa sobre las transacciones, similar el IVA.

Uno de los impuestos que mayor recaudación posee es el IVA. A continuación se presentarán los argumentos económicos, de eficiencia y equidad sobre este tributo.

\section{IMPUESTO AL VALOR AGREGADO}

EI IVA es un impuesto polémico. Implementado en los años 70s reemplazó un esquema de impuestos al consumo que muchas veces producía una cascada ${ }^{2}$ de impuestos implicando muchas distorsiones. Desde ese punto de vista, el IVA es considerado un impuesto muy eficiente en términos de recaudación, logrando grandes montos con relativamente bajos costos de fiscalización y sin el inconveniente de agregar impuesto sobre impuesto.

Desde el punto de vista de la equidad, el IVA tiene aspectos negativos ya que se considera regresivo, debido a que personas de menores ingresos consumen el $100 \%$ de su ingreso en bienes y servicios afectos al IVA, por lo que terminan pagando el $19 \%$ de su renta por este impuesto. La situación no es la misma para contribuyentes de mayores rentas, que consumen menos que su ingreso, permitiéndoles generar ahorro. Por lo tanto se concluye que terminan pagando menos del $19 \%$ de sus ingresos. Como medida compensatoria, se argumenta que programas bien focalizados de subsidio a las personas con menores ingresos debería lograr eliminar tal inequidad. En teoría parte de los recursos para implementar los subsidios podrían ser generados por la población de mayores ingresos. Esto, debido a que se

"El problema práctico
para la implementación
de un sistema tributario
diferenciado es conocer
las funciones de
bienestar de muchos
individuos, lo cual es un
problema no resuelto en
economía"

estima que el $20 \%$ de la población con mayores ingresos paga casi el $50 \%$ de la recaudación del IVA, mientras que el $20 \%$ de menores ingresos contribuye con el $7 \%$ del total del IVA recaudado ${ }^{3}$.

\section{¿QUÉ HACEAL IVATAN EFICIENTE?}

Si bien algunos países poseen más de dos categorías para este impuesto, el denominado IVA diferenciado, políticas de este tipo pueden generar problemas de sustitución desde bienes con mayores impuestos a bienes con menores impuestos.

A pesar de todos los inconvenientes que tiene el IVA, sus principales ventajas son la fácil fiscalización y su capacidad recaudadora con bajos costos de fiscalización. Es así que se estima que subir el IVA de $19 \%$ a $20 \%$ podría implicar más de mil millones dólares de nueva recaudación ${ }^{4}$.

No podemos descartar impuestos aplicados sobre bienes que la sociedad desearía desalentar, como el tabaco y licores. Sin embargo, su capacidad recaudadora es muy menor en relación al IVA y además en la medida que se incrementan estos impuestos los incentivos al contrabando aumentan, y con ellos el costo social. Los impuestos verdes 0 a la contaminación poseen las mismas características que los impuestos a los males previamente mencionados.

Por la tanto, en caso de que el actual gobierno se propusiera legislar por un alza de impuesto a las transacciones el candidato sería un alza del IVA, procurando implementar los programas sociales necesarios para no perjudicar a los grupos sociales más vulnerables. $\mathbf{E}$

1. Como Costo Social se refiere a la suma de costo directos de fiscalización para implementar las políticas impositivas, así como la reducción de la utilidad de los agentes que no es transferida al Estado por medio de la recaudación tributaria.

2. Ganga Contreras, Francisco, Cabello Herrera, Ximena, \& Piñones Santana, M. Angélica. (2014). Estado e impuestos indirectos en Chile y Latinoamérica: análisis del período 2000 - 2011. Visión de futuro, 18(1) Recuperado en 14 de mayo de 2018, de http://www.scielo.org.ar/scielo.php?script=sci_arttext\&pid=S1668$87082014000100003 \& \operatorname{lng}=$ es\&tlng=es.

3 y 4. http://www.economiaynegocios.cl/noticias/noticias.asp?id=105756 